\title{
Aging reduces kisspeptin receptor (GPR54) expression levels in the hypothalamus and extra-hypothalamic brain regions
}

\author{
USHODAYA MATTAM $^{1}$, NOBLE KUMAR TALARI ${ }^{1}$, VENKATA RAMANA THIRIVEEDI ${ }^{1}$, MOHAMMED FAREED ${ }^{1}$, \\ SATHYA VELMURUGAN ${ }^{2}$, KALYANKAR MAHADEV ${ }^{3}$ and NARESH BABU V. SEPURI ${ }^{1}$ \\ ${ }^{1}$ Department of Biochemistry, School of Life Sciences; ${ }^{2}$ National Institute of Animal Biotechnology; \\ ${ }^{3}$ School of Medical Sciences, University of Hyderabad, Hyderabad, Telangana 500046, India
}

Received June 19, 2020; Accepted March 3, 2021

DOI: $10.3892 /$ etm.2021.10451

\begin{abstract}
Aging leads to the diminished pulsatile secretion of hypothalamic gonadotropin-releasing hormone $(\mathrm{GnRH})$. Kisspeptin (Kp), the upstream regulator of the hypothalamic-pituitary-gonadal (HPG) axis, regulates $\mathrm{GnRH}$ synthesis and release through its cognate receptor, G-protein coupled receptor 54 (GPR54). In turn, GnRH regulates GPR54 expression. GnRH administration into the third ventricle has been shown to induce neurogenesis in different brain regions in old age. However, aging-associated changes in hypothalamic and extra-hypothalamic GPR54 expression were unclear. Therefore, the expression levels of GPR54 were evaluated in various brain regions of adult (age, 3-4 months) and old (age, 20-24 months) male Wistar rats in the present study. In the hypothalamus, mRNA and protein levels of Kp and GPR54 were identified to be significantly decreased in old age. Furthermore, $G n R H 1$ expression in the hypothalamus was analyzed to observe the functional consequence of a reduced Kp-GPR54 system in the hypothalamus. It was found that hypothalamic GnRHI levels were significantly decreased in old age. As GnRH regulates GPR54 levels, GPR54 was examined in extra-hypothalamic regions. GPR54 levels were found to be significantly decreased in the hippocampus and medulla and pons in old-age rats when compared to adult rats. Notably, GPR54 expression was observed in the frontal lobe, cortex, midbrain and cerebellum of adult and old-age rats; however, the difference between the two groups was not statistically significant. To the best of our knowledge, this is the first study that provides the quantitative distribution of GPR54 in different brain regions during aging. Thus, the reduced levels of Kp and its receptor, GPR54 in the hypothalamus could be
\end{abstract}

Correspondence to: Dr Naresh Babu V. Sepuri or Dr Ushodaya Mattam, Department of Biochemistry, School of Life Sciences, University of Hyderabad, Prof. C.R. Rao Road, Gachibowli, Hyderabad, Telangana 500046, India

E-mail: nareshuohyd@gmail.com

E-mail: mattamusha@gmail.com

Key words: aging, kisspeptin, G-protein coupled receptor 54, gonadotropin-releasing hormone, brain cumulatively responsible for reduced levels of GnRH observed in old age.

\section{Introduction}

Aging is a complex process and is associated with several alterations, including a decline in the activity of the hypothalamic-pituitary-gonadal (HPG) axis, hormonal abnormalities, cognitive impairments and depression (1). Aging is accompanied by a decrease in pulsatile luteinizing hormone (LH) secretion due to a decline in the pulsatile secretion of gonadotropin-releasing hormone $(\mathrm{GnRH}) / \mathrm{LH}(2-4)$. A recent study describes that aging could be accompanied by decreased expression of arcuate (ARC) nucleus kisspeptin (Kp) along with neurokinin B and dynorphins (5). However, neuronal projections expressing Kp from the hypothalamic anteroventral periventricular nucleus (AVPV) play a pivotal role in the regulation of GnRH along with $\mathrm{Kp}$ expressed in the ARC nucleus (6). Kps are a family of peptide products known to stimulate GnRH secretion and play an important role in fertility and reproduction by regulating the HPG axis. Kp acts through G-protein coupled receptor 54 (GPR54) and numerous studies reported the presence and functions of Kp or GPR54 in various types of tissue and organs (7-9). In the brain, the Kp-GPR54 system functions predominantly to control the reproductive process (10). In the hypothalamus, the increased GPR54 signaling initiates puberty, whereas its loss of function delays pubertal onset $(11,12)$.

In addition to its major function as an upstream regulator of the HPG axis, the Kp-GPR54 system also triggers several other signaling pathways. The role of the Kp-GPR54 system in reproductive and non-reproductive functions was indicated in a previous study (13). Numerous studies reported that $\mathrm{Kp}$ induces phospholipase $\mathrm{C}$ enzyme activity through GPR54 (14,15). Additionally, it has been shown that mutation of GPR54 elicits prolonged activation of the ERK signaling pathway in response to Kp (16). Furthermore, loss of function of GPR54 is known to be associated with hypogonadotropic hypogonadism (17). Therefore, the loss or gain of function of the GPR54 receptor determines the specificity and importance of appropriate signaling of the Kp-GPR54 system (13).

The Kp-GPR54 system has been extensively investigated in the hypothalamus. Certain studies suggest that GPR54 is 
expressed in the hippocampus and amygdala $(8,9)$. However, its expression in other brain regions, such as the medulla, pons, cerebellum, midbrain, frontal lobe and cortex requires further investigation. Moreover, age-induced alterations, if any, could elucidate the potential role of Kp-GPR54 in other regions of the brain besides the hypothalamus. In aging, GnRH administration has been shown to promote neurogenesis in the hypothalamus, hippocampus and other brain regions. Additionally, GnRH travels to other brain regions to affect the aging process (18). Furthermore, GnRH regulates GPR54 levels (19). Therefore, the aim of the present study was to evaluate the expression of GPR54 in different brain regions, including the hypothalamus, hippocampus, medulla, pons, cerebellum, midbrain, frontal lobe and cortex in adult (age, 3-4 months) and old (age, 20-24 months) male Wistar rats.

\section{Materials and methods}

Animals. Male Wistar rats representing two different age groups, adult (age, 3-4 months; n=8) and old (age, 20-24 months; $n=8$ ) were procured from the Indian Council of Medical Research Institute, National Institute of Nutrition (Hyderabad, India) for use in the present study. The rats were housed at room temperature $\left(23-24^{\circ} \mathrm{C}\right)$, in 12-h light/dark cycle and relative humidity of 55-60\%. Food and water were provided ad libitum and cage changes were at random intervals. The study was approved by the Institutional Animal Ethics Committee (IAEC) of the University of Hyderabad (approval no. UH/IAEC/NBVS/2019-I/03). All procedures were performed according to IAEC guidelines

The rats were anesthetized with $290 \mathrm{mg} / \mathrm{kg}$ body weight avertin via intraperitoneal injection and sacrificed by decapitation. The brains were removed by dissection and the various regions, including the hypothalamus, hippocampus, cortex, midbrain, frontal lobe, medulla and pons and cerebellum were isolated $(20,21)$. All tissue samples were stored at $-80^{\circ} \mathrm{C}$ until analysis.

RNA isolation and reverse transcription. Total RNA was isolated from the hypothalamus and other regions of the brain using TRIzol ${ }^{\circledR}$ (Thermo Fisher Scientific, Inc.) according to the manufacturer's protocol. Total RNA was dissolved in nuclease-free water and quantified using a NanoDrop ${ }^{\mathrm{TM}}$ Spectrophotometer (Thermo Fisher Scientific, Inc.). cDNA was synthesized using an iScript cDNA Synthesis Kit (Bio-Rad Laboratories, Inc.).

Quantitative (q)PCR. qPCR was performed using the SYBR ${ }^{\mathrm{TM}}$ Green (Applied Biosystems; Thermo Fisher Scientific, Inc.) detection method to assess GPR54, Kiss1 and GnRH1 mRNA expression levels. qPCR was performed using $40 \mathrm{ng}$ cDNA from each sample (Adult, $n=4$; Old, $n=4$ ). By using the first-strand cDNA template from each sample, the target and reference genes were amplified separately. The primer sequences for GPR54, Kiss1, GnRH1 and GAPDH were as follows: GPR54 forward, 5'-GCGGCCACAGATGTCACTTT-3' and reverse, 5'-AGGTGGGCAGCGGATAGA-3'; Kiss 1 forward, 5'-GCT GCTGCTTCTCCTCTGTGT-3' and reverse, 5'-CTGTTG GCCTGTGGGTTCA-3'; GnRH1 forward, 5'-GCAGAACCC CAGAACTTCGA-3' and reverse, 5'-CAACGCCAAGGAGCT
CAAGT-3'; GAPDH forward, 5'-TATCACTCTACCCACGGC AAG-3' and reverse, 5'-ATACTCAGCACCAGCATCACC-3'. Amplification was performed using an Applied Biosystems Power SYBR-Green PCR Master Mix (2X; Thermo Fisher Scientific, Inc.) and Applied Biosystems ${ }^{\mathrm{TM}} 7500$ Real-Time PCR System (Thermo Fisher Scientific, Inc.). The reaction set-up for PCR was as follows: $1 \mu 1$ 10-pmol forward primer, $1 \mu 1$ 10-pmol reverse primer, $10 \mu 1$ Power SYBR-Green PCR Master Mix (2X) and $8 \mu \mathrm{l}(40 \mathrm{ng})$ cDNA in a total reaction volume of $20 \mu \mathrm{l}$. The standard thermocycling conditions were as follows: Initial denaturation at $95^{\circ} \mathrm{C}$ for $10 \mathrm{~min}$, followed by 40 cycles of denaturation at $95^{\circ} \mathrm{C}$ for $15 \mathrm{sec}$ and $60^{\circ} \mathrm{C}$ for $1 \mathrm{~min}$. Single amplification of the product and absence of primer-dimer formation was confirmed by dissociation curves. Cycle threshold $(\mathrm{Cq})$ values were taken from the exponential phase of PCR amplification. The expression levels of target genes, GPR54, Kiss 1 and GnRHI were normalized to GAPDH expression $(\triangle \mathrm{Cq}=$ target gene $\mathrm{Cq}-\mathrm{GAPDH} \mathrm{Cq})$ and the relative quantity of target mRNA expression in each sample was equal to $2^{-\Delta \Delta \mathrm{Cq}}(22)$.

Western blotting. Tissue samples were Dounce homogenized in lysis buffer (50 mM Tris- $\mathrm{HCl}, \mathrm{pH} 8.0,150 \mathrm{mM} \mathrm{NaCl}$, $1 \%$ Nonidet P-40 and $0.5 \%$ sodium deoxycholate) supplemented with protease inhibitors to a final concentration of $10 \%$ homogenate. Lysates were sonicated and centrifuged at $10,000 \mathrm{x}$ g for $5 \mathrm{~min}$ at $4^{\circ} \mathrm{C}$, clear supernatants were collected and the protein concentration was estimated using the Bradford Method (23). Each sample (50 $\mu \mathrm{g}$ protein/lane) was separated by $12 \%$ SDS-PAGE (24) and electrophoretically transferred onto a nitrocellulose membrane. Blocking was performed with $5 \%$ non-fat milk for $1 \mathrm{~h}$ at room temperature and washed with PBS with $0.05 \%$ tween 20 (PBST) three times each $5 \mathrm{~min}$. The membrane was probed with the following primary antibodies: Anti-GPR54 (dilution, 1:1,000; cat. no. GTX100374; GeneTex, Inc.) and anti-Kp (dilution 1:1,000; cat. no. GTX337642; GeneTex, Inc.) antibodies for $12 \mathrm{~h}$ at $4^{\circ} \mathrm{C}$, washed three times at 5 min each with PBS followed by anti-rabbit horseradish peroxidase-conjugated secondary antibody for $2 \mathrm{~h}$ at room temperature (dilution, 1:2,000; cat. no. SC2357; Santa Cruz Biotechnology, Inc.). The blots were washed with PBS and developed using ECL ${ }^{\text {TM }}$ Prime (Cytiva) and an imaging system (Chemidoc; Bio-Rad Laboratories, Inc.). Densitometry was performed using ImageJ $1.49 \mathrm{v}$ Software (National Institutes of Health).

Statistical analysis. Data were analyzed using unpaired Student's t-test for comparison between the two groups. Results are expressed as the mean \pm standard error of the mean and $\mathrm{P}<0.05$ was considered to indicate a statistically significant difference. SigmaPlot 11.0 software (Systat Software, Inc.) was used for statistical analysis.

\section{Results}

Aging-associated decreases in GPR54, Kiss1 and GnRH1 $m R N A$ levels are observed in the hypothalamus. Neuronal projections expressing Kp from the hypothalamic AVPV region play a pivotal role in the regulation of $\mathrm{GnRH}$ along with $\mathrm{Kp}$ expressed in the ARC nucleus (6). Age-dependent decline 
A

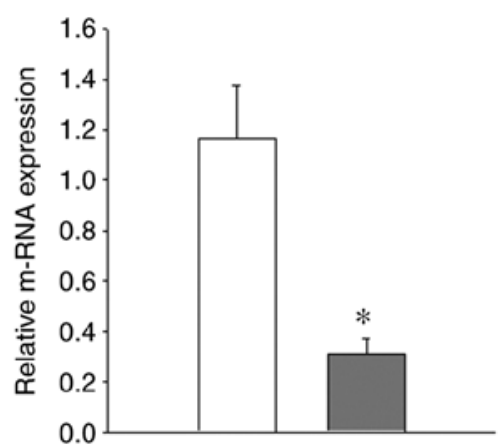

B

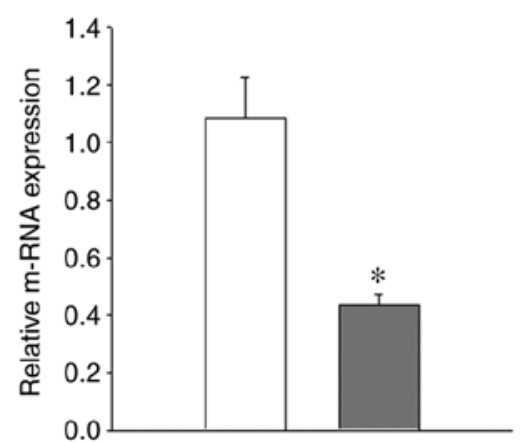

C

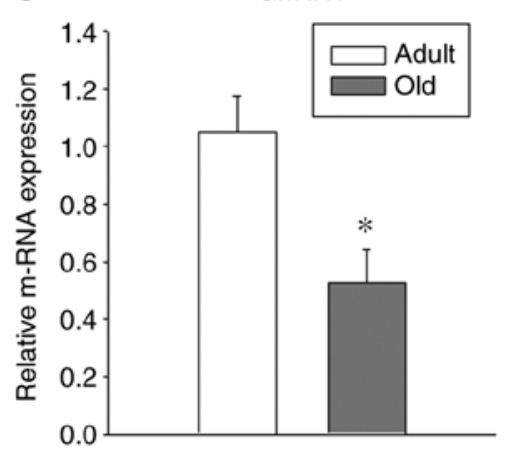

Figure 1. Hypothalamic expression of Kiss1, GPR54 and GnRH1 reduces in old age. mRNA expression of hypothalamic (A) Kiss1, (B) GPR54 and (C) GnRH1 in adult (age, 3-4 months) and old-age (age, 20-24 months) rats (n=4). Relative mRNA expression is normalized to internal reference gene GAPDH. Each value is presented as the means \pm SEM. ${ }^{*} \mathrm{P}<0.05$. Kiss1, KiSS-1 metastasis suppressor; GPR54, G protein-coupled receptor-54; GnRH1, gonadotropin releasing hormone 1.

in Kp expression levels has been observed in the hypothalamic ARC nucleus of the brain (5). However, it remains unclear whether AVPV Kp levels also alter with aging. Furthermore, it is essential to determine the steady-state levels of the $\mathrm{Kp}$ target receptor, GPR54, to understand the Kp-GPR54 mediated signaling mechanism.

To investigate the age-associated changes of GPR54, Kiss 1 and $G n R H$ in the hypothalamus, the hypothalamic brain region from adult and old-aged rats was isolated in the present study. qPCR was performed from total cDNA to estimate the relative mRNA levels of GPR54, Kiss1 and $G n R H$. Notably, a significant decrease was observed in the mRNA levels of GPR54, Kiss 1 and $G n R H$ in old-age rats when compared with adult rats (Fig. $1 ; \mathrm{P}<0.05)$. These results indicate the important role of GPR54, Kissl and GnRHI in the aging process.

Aging-associated decreases in GPR54 and Kp protein levels are observed in the hypothalamus. As an aging-associated decrease was observed in GPR54 and Kiss 1 mRNA levels in the hypothalamus, the present study investigated whether GPR54 and Kp protein levels were also altered during the aging process. To examine this, western blotting was conducted to analyze the protein levels of GPR54 and Kp. A decrease in GPR54 and Kp protein levels was observed in the hypothalamus of the old-age rats when compared with that of the adult rats (Fig. 2; $\mathrm{P}<0.05$ ). These results indicate the strong association between GPR54 and Kp levels at the mRNA and protein levels.

Aging-associated alterations in GPR54 expression are observed in the extra-hypothalamic brain region. The Kp-GPR54 system has been evaluated extensively in the hypothalamus. However, few studies reported the expression of GPR54 in the amygdala and hippocampus. Furthermore, it has been shown that the Kp-GPR54 system modulates real-time synaptic transmission in the hippocampus, likely through signaling pathways and their associated trophic factors and tyrosine kinase receptors (25). This indicates that the Kp-GPR54 system has a selective function in other brain regions besides the hypothalamus.

Aging is characterized by diminished neurogenesis and $\mathrm{GnRH}$ administration is known to reverse this age-induced effect in the hypothalamus and hippocampus. Furthermore, GnRH administration appeared to exert similar effects in other brain regions (18), which indicates that GnRH travels within the brain to promote neurogenesis. Additionally, $\mathrm{GnRH}$ is also known to regulate GPR54 levels (19). In the present study, an age-dependent reduction of GnRH levels was observed in the hypothalamus region. However, whether expression of GPR54 regulates the aging process in extra-hypothalamic regions requires further investigation. To date, to the best of our knowledge, no studies have documented the expression of GPR54 in other regions of the brain.

To evaluate whether GPR54 is expressed in other regions of the brain, extra-hypothalamic brain regions, such as the hippocampus, frontal lobe, cortex, midbrain, cerebellum, medulla and pons were isolated and the mRNA and protein levels of GPR54 were evaluated.

In the hippocampus, GPR54 mRNA was observed in adult and old-age rats; however, the difference between adult and old-age rats was not statistically significant (Fig. 3). Indeed, the protein levels of GPR54 were significantly decreased in old-age rats when compared with adult rats (Fig. 4A; $\mathrm{P}<0.05$ ). In the medulla and pons, the relative mRNA expression of GPR54 was significantly increased in old-age rats when compared with that in adult rats (Fig. 3; $\mathrm{P}<0.05$ ). By contrast, the protein levels were decreased in old-age rats compared with that in adult rats (Fig. $4 \mathrm{~B} ; \mathrm{P}<0.05)$. In the frontal lobe, the relative mRNA expression of GPR54 was significantly increased in old-age rats when compared with that in adult rats (Fig. 3; $\mathrm{P}<0.05$ ). Although GPR54 protein expression was observed in the adult and old-age rat groups, the difference between adult and old age rats was not statistically significant (Fig. 5).

GPR54 mRNA levels were significantly increased in the cortex of old-age rats when compared to that in adult rats (Fig. 3; $\mathrm{P}<0.05)$; however, the same tendency was not observed in GPR54 protein expression levels where the difference between adult and old-age rats was not statistically significant (Fig. 5). In the midbrain, similar findings to the frontal lobe and cortex were observed, that is to say, a significant increase in GPR54 mRNA levels was observed in old-age rats when compared with adult rats (Fig. 3; $\mathrm{P}<0.05$ ) and no significant difference in GPR54 protein levels was observed between the two groups (Fig. 5). Although GPR54 mRNA and protein expression was 
A
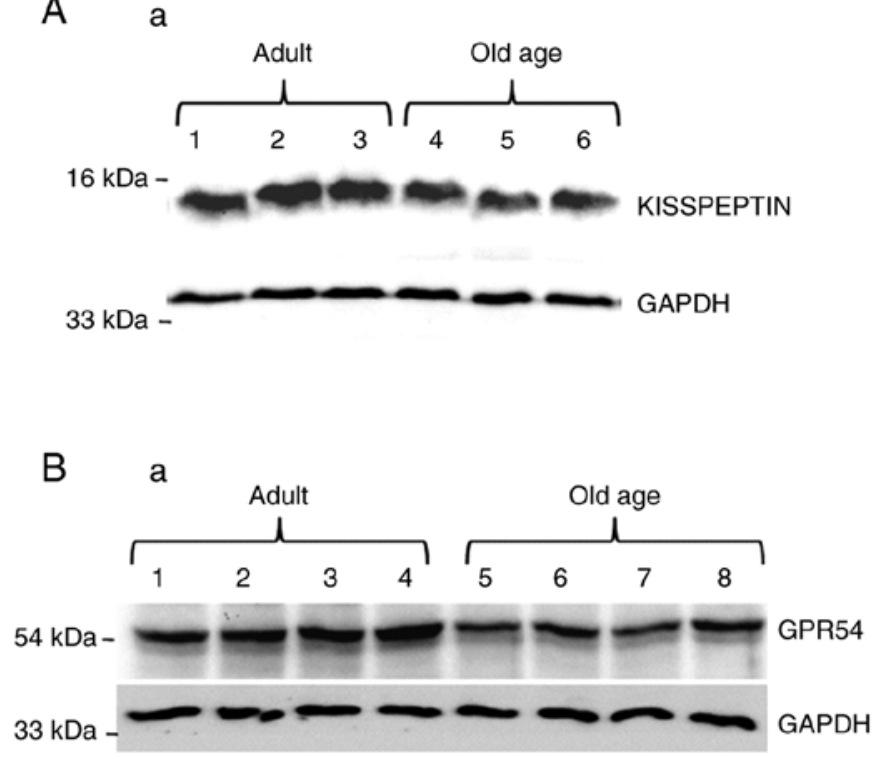

b
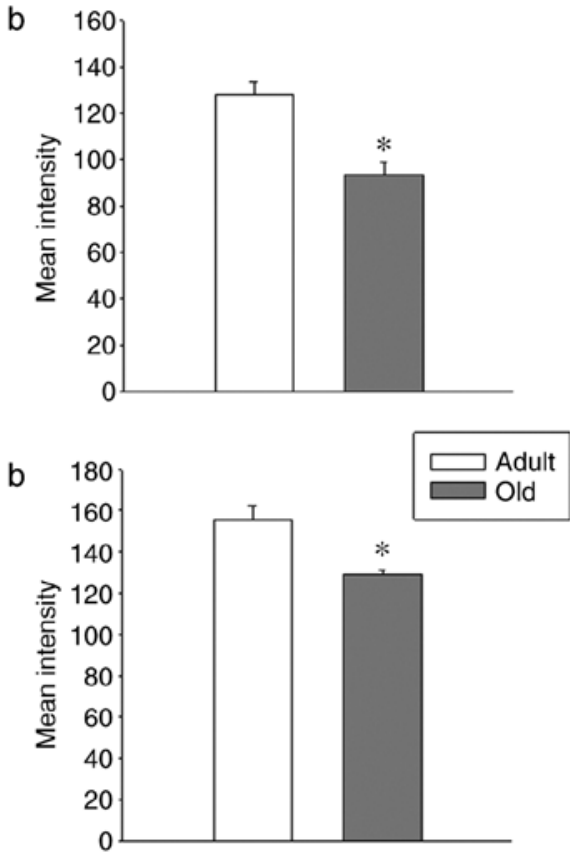

Figure 2. Hypothalamic expression of kisspeptin and GPR54 protein levels reduce in old age. Reduced expression levels of kisspeptin in the hypothalamus of adult (age, 3-4 months) and old-age (age, 20-24 months) rats ( $\mathrm{n}=3$ to 4), as presented by (A-a) western blotting and (A-b) densitometry. Reduced expression levels of GPR54 in the hypothalamus of adult and old-age rats ( $n=3$ to 4 ), as presented by (B-a) western blotting and (B-b) densitometry. GAPDH served as the loading control. $n=3$ in case of kisspeptin immunoblotting and $n=4$ in case of GPR54. Values are presented as means \pm SEM. ${ }^{*}<0.05$. GPR54, G protein-coupled receptor-54.

observed in adult and old-age rats in the cerebellum, the difference was not statistically significant (Figs. 3 and 5).

\section{Discussion}

Kp was initially recognized as a metastasis suppressor (26). Subsequently, a strong association between the Kp-GPR54 system and the HPG axis was identified in the control of reproduction. Kp mediates pulsatile secretion of gonadotropins, $\mathrm{LH}$ and follicle stimulating hormone, via GnRH (6). During old age, such pulsatile LH secretion is reduced due to the deterioration of the $\mathrm{GnRH} / \mathrm{LH}$ pulse generator $(3,4)$. A previous study indicated that this is accompanied by a decrease in the expression of $\mathrm{Kp}$, dynorphin and neurokinin $\mathrm{B}$ during the aging process (5). The role of the Kp-GPR54 system has been extensively investigated in the hypothalamus. Although certain studies state that GPR54 is also expressed in the hippocampus and amygdala $(8,9)$, its association with aging has not been elucidated. Notably, in a recent study, the functional importance of the Kp-GPR54 system was evaluated in rat brain hippocampus and neuronal cell lines (27). Therefore, it is considered important to evaluate GPR54 expression in extra-hypothalamic regions. Furthermore, to the best of our knowledge, there are no studies on GPR54 expression and its association with aging in extra-hypothalamic brain regions, such as the midbrain, frontal lobe, cortex, cerebellum, medulla and pons.

Aging leads to the loss of various physiological functions and ultimately decreases life span (1). In addition to its role in regulating sex hormones, GnRH was known to restore aging-impaired neurogenesis (18). Previously, it was demonstrated that GnRH treatment induces neurogenesis in the hypothalamus, hippocampus and other brain regions (18). Kps are the upstream regulator of $\mathrm{GnRH}$ and controlled regulation of the Kp-GPR54 system could be important for aging. Notably, Kp expression was controlled by oestradiol, while GPR54 expression was regulated by GnRH (19). Thus, in line with existing literature, the present study aimed to examine the expression of Kp, GPR54 and GnRH in different brain regions of rats to elucidate the molecular changes that occur during aging. To the best of our knowledge, this is the first study describing the expression of GPR54 and its association with aging in various brain regions.

To evaluate the age-associated changes of Kp, GPR54 and GnRH in the hypothalamus, the hypothalamus of adult and old-age rats was examined in the present study. Numerous studies have described the presence and pivotal role of $\mathrm{Kp}$ and GPR54 in the hypothalamus (28-31). Furthermore, in several species, including humans, peripheral administration of $\mathrm{Kp}$ is known to stimulate $\mathrm{GnRH}$ release in the hypothalamus (1,29,32-38). All of these studies demonstrate that the Kp-GPR54 system plays an important role in pubertal maturation, reproduction and $\mathrm{GnRH}$ release. In the present study, hypothalamic GPR54 mRNA expression was demonstrated to be significantly reduced in old-age rats when compared with adult rats. Accordingly, hypothalamic GPR54 protein levels were also significantly decreased in the old-age rats. Similarly, hypothalamic Kp mRNA and protein levels were observed to be decreased in old-age rats when compared with adult rats. A previous study has shown that $\mathrm{Kp}$ regulates GnRH mRNA expression (35). Various lines of evidence indicate that GnRH levels are decreased in old age $(1,36,37)$. Furthermore, hypothalamic $G n R H 1$ mRNA levels were identified to be significantly decreased in old-age rats when compared to adult rats in the present study. GnRH protein levels were not evaluated, as it is a well-established fact that aging diminishes GnRH secretion 

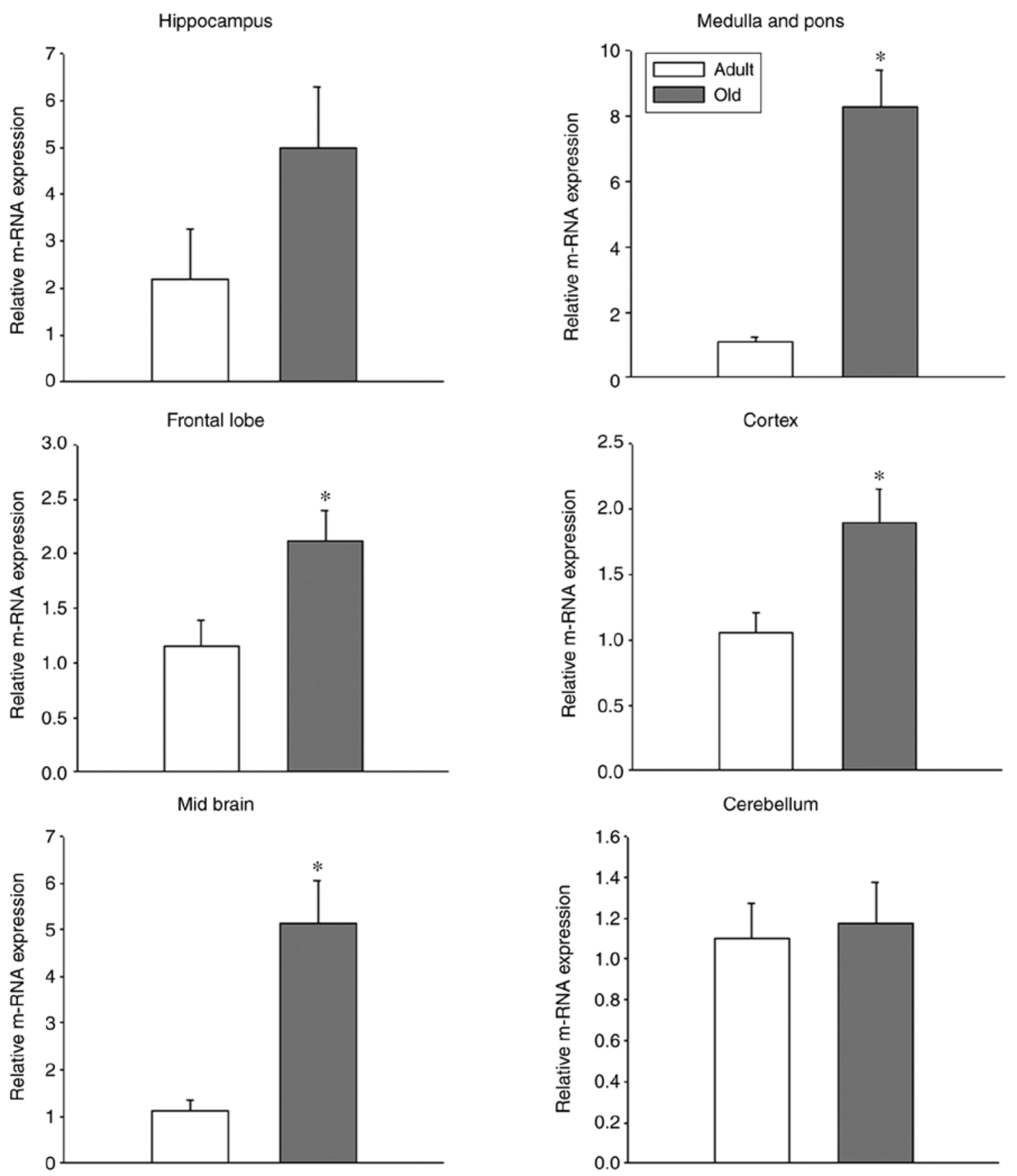

Figure 3. Age-induced alterations in mRNA expression of GPR54 in extra-hypothalamic brain regions of adult (age, 3-4 months) and old-age (age, 20-24 months) rats $(\mathrm{n}=4)$. Relative mRNA expression was normalized to internal reference gene GAPDH. Values are presented as means \pm SEM. ${ }^{*} \mathrm{P}<0.05$. GPR54, G protein-coupled receptor-54.

in rodents and mammals $(1,36,37)$. Decreased hypothalamic Kp levels may be responsible for reduced levels of hypothalamic GnRH1. In the present study, it was hypothesized that decreased expression of GPR54 in the hypothalamus during aging may be due to decreased GnRH expression. However, further studies are required to elucidate the functional importance of the Kp-GPR54 system in aging.

Initially, Lee et al (9) identified GPR54 mRNA expression across rat brain regions through Northern blot analysis and in situ hybridization techniques. The authors observed that GPR54 mRNA was predominant in limbic brain regions, including the hypothalamus, hippocampus and periaqueductal grey regions. However, a limitation of the study was the lack of a detailed quantitative description of GPR54 protein expression (9). GnRH neurons co-expressing GPR54 have been confirmed by in situ hybridization and feedback regulation of gonadotropin secretion by the Kp-GPR54 system was also demonstrated (39). However, in situ hybridization of GPR54 mRNA was identified to be similar among juvenile and adult mice (40). By contrast, GnRH neurons expressing GPR54 were found to increase from the postnatal period to adulthood in mice (41).

As GnRH induces neurogenesis in hypothalamic and extra-hypothalamic regions during aging and as it regulates GPR54 expression, the present study investigated GPR54 expression in extra-hypothalamic regions, including the frontal 
A

a Hippocampus

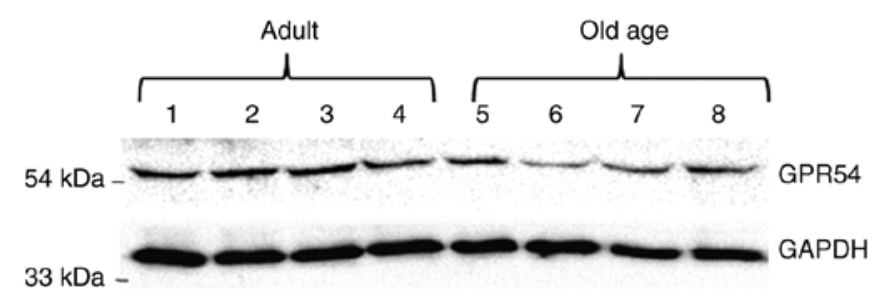

B

a Medulla and pons

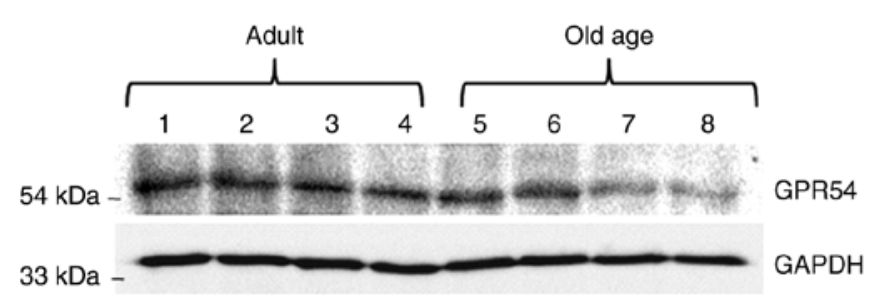

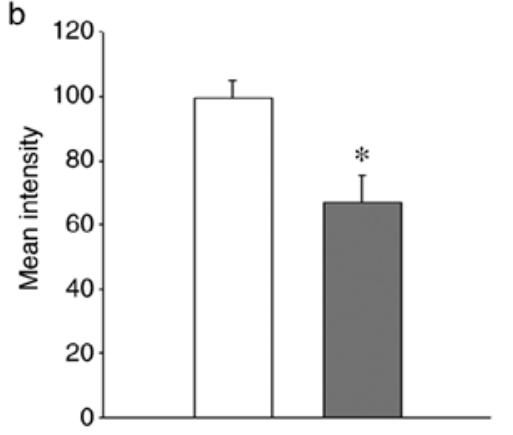

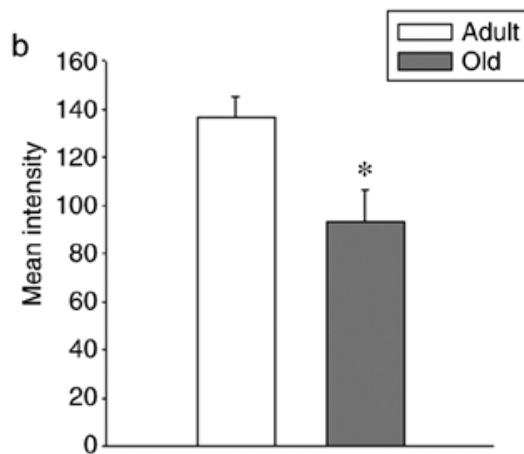

Figure 4. GPR54 protein levels in the hippocampus and medulla and pons were reduced in old-age rats (age, 20-24 months) when compared with adult (age, 3-4 months) rats $(\mathrm{n}=4)$. (A-a) Western blotting and $(\mathrm{A}-\mathrm{b})$ densitometry demonstrating reduced GPR54 protein levels in the hippocampus of old-age rats. (B-a) Western blotting and (B-b) densitometry demonstrating reduced GPR54 protein levels in the medulla and pons regions of old-age rats. GAPDH served as the loading control. Values are presented as means \pm SEM. ${ }^{*} \mathrm{P}<0.05$. GPR $54, \mathrm{G}$ protein-coupled receptor- 54 .

\section{A Frontal lobe}

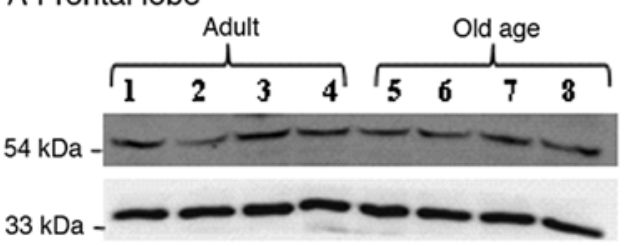

GPR54

GAPDH

\section{B Cortex}

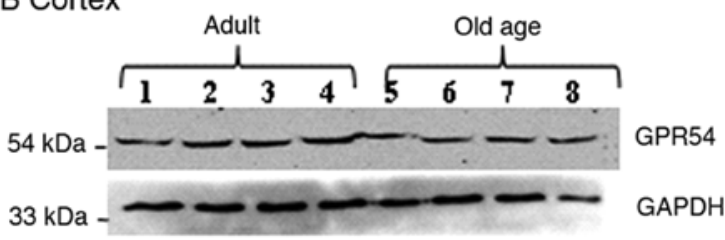

C Mid brain

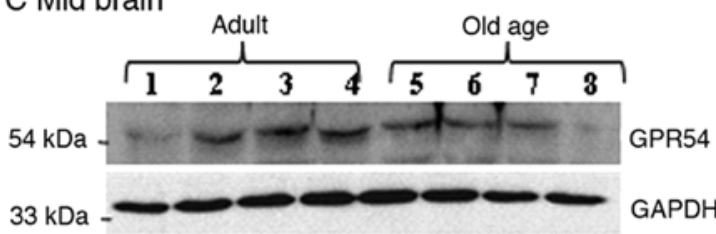

D Cerebellum

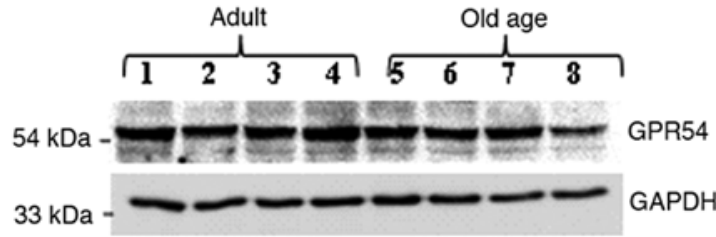

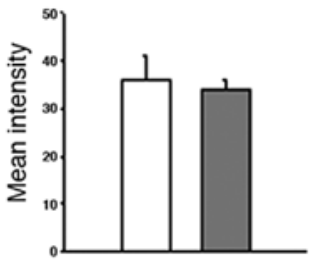
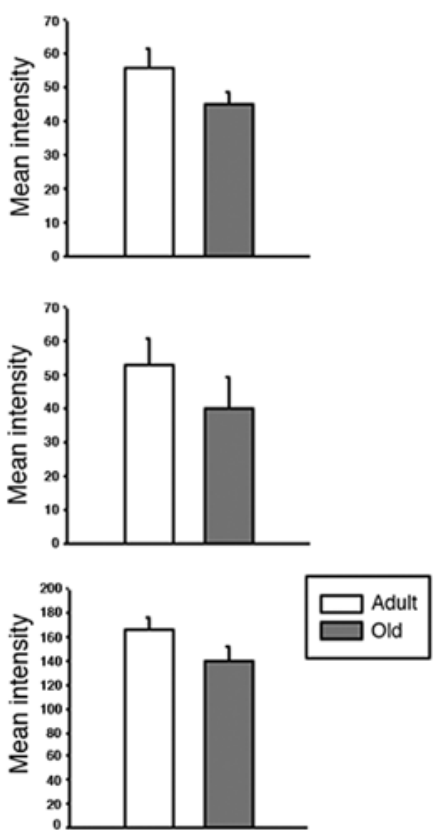

Figure 5. Age-induced alterations in GPR54 levels in the frontal lobe, cortex, midbrain and cerebellum of adult (age, 3-4 months) and old-age (age, 20-24 months) rats $(n=4)$. GAPDH served as a loading control. (A) Western blotting and densitometry of GPR54 in the frontal lobe. (B) Western blotting and densitometry of GPR54 in the cortex. (C) Western blotting and densitometry of GPR54 in the midbrain. (D) Western blotting and densitometry of GPR54 in the cerebellum. Values are presented as means \pm SEM.. GPR54, G protein-coupled receptor-54. 
lobe, cortex, midbrain, cerebellum, hippocampus, medulla and pons. In the hippocampus, GPR54 protein levels were significantly decreased in old-age rats when compared with that in adult rats. However, the difference in GPR54 mRNA expression between those groups was not identified to be statistically significant. A previous study identified that age-impaired neurogenesis in the hippocampus was prevented by GnRH treatment (18). In the present study, it was hypothesized that decreased GPR54 expression in the hippocampus could be attributed to the decreased synthesis of GnRH in the hypothalamus. In the medulla and pons, GPR54 mRNA levels were significantly increased in old-age rats when compared to that of adult rats. In contrast to the mRNA levels, GPR54 protein levels were decreased in the old-age rats when compared to the adult rats. The decrease in GPR54 protein expression could be due to GnRH control, as GnRH is known to travel to other brain regions, not just the hypothalamus and hippocampus (19). In the frontal lobe, the GPR54 mRNA levels were significantly increased in old-age rats when compared to that of adult rats. However, the difference in GPR54 protein expression between old age rats and adult rats was not statistically significant. Similar results were observed in the cortex and midbrain.

Various factors are known to affect mRNA and protein expression in aging. For example, perturbed translational control $(42,43)$. It is evident that aging is accompanied by a loss of translational control that leads to the shutdown of protein synthesis of specific mRNAs $(42,43)$. In general, it preserves the protein homeostasis that prevents the production of excessive quantities of undesirable proteins for normal cellular function $(42,43)$. Regulation of protein synthesis is a common determinant of longevity $(42,43)$. Therefore, reducing translational factors that reduce mRNA translation could be an adaptive response to increase longevity or it could be associated with an age-associated decline in cellular functions $(42,43)$. In the present study, GPR54 mRNA and protein expression in the cerebellum were not observed to be significantly different between old-age and adult rats. The present study hypothesized that this could be due to a deficiency in translation of GPR54 in these particular regions, however, further studies are required to confirm this hypothesis.

There are only a small number of studies regarding the function of GPR54 across extra-hypothalamic brain regions, therefore this is less well understood. In one study, the presence of the Kp-GPR54 system in the dentate gyrus of the hippocampus has been shown to modulate the synaptic excitability via the MAP kinase pathway $(25,44)$. Another study described the presence of GPR54 in all three layers of the dentate gyrus and in the CA3 pyramidal cell layer region, indicating the role of GPR54 in the proper functioning of the hippocampus (41). In our recent study, $\mathrm{Kp}$ was demonstrated to preserve mitochondrial function by inducing autophagy/mitophagy in the hippocampus of aging rat brains and neuronal cell lines (27). The mechanistic details of Kp-induced autophagy/mitophagy were also demonstrated. The silencing of GPR54 was shown to diminish the effects of Kp-induced autophagy/mitophagy. Thus, as Kp protects mitochondrial health in the hippocampus of rat brains, it could also be used as a therapeutic target in hippocampus-associated impairments, such as memory, cognitive aging and other diseases associated with mitochondrial dysfunction.
The present study supports previous findings on GPR54 expression outside the hypothalamic regions. In addition, the altered expression of GPR54 among adults and old-age rats suggests a role of GPR54 in the aging process, although whether it is a cause or effect remains unknown. Thus, further investigations are required to investigate the functional significance of GPR54 in different brain regions with respect to aging.

\section{Acknowledgements}

Not applicable.

\section{Funding}

The present study was supported by a National Post-Doctoral Fellowship grant (to UM; grant. no. PDF/2016/000191) from the Department of Science and Technology, Science and Engineering Research Board, Government of India and New Delhi. Department of Biotechnology, Government of India (to NBVS; grant no. BT/PR10319/BRB/10/1267/2013).

\section{Availability of data and materials}

The datasets used and/or analyzed during the current study are available from the corresponding author on reasonable request.

\section{Authors' contributions}

UM performed the research. NKT, VRT and MF helped UM with the experiments. UM and NBVS designed the research. UM, KM and NBVS analyzed the data. UM, NKT, KM, SV and NBVS discussed and interpreted the data. UM, NKT and NBVS wrote the paper. NBVS and UM can confirm the authenticity of all the raw data. All authors read and approved the final version of the manuscript.

\section{Ethics approval and consent to participate}

The study was approved by the Institutional Animal Ethics Committee (IAEC) of the University of Hyderabad (approval no. UH/IAEC/NBVS/2019-I/03). All procedures were performed according to IAEC guidelines

\section{Patient consent for publication}

Not applicable.

\section{Competing interests}

The authors declare that they have no competing interests.

\section{References}

1. Veldhuis JD: Aging and hormones of the hypothalamo- pituitary axis: Gonadotropic axis in men and somatotropic axes in men and women. Ageing Res Rev 7: 189-208, 2008.

2. Steiner RA, Bremner WJ, Clifton DK and Dorsa DM: Reduced pulsatile luteinizing hormone and testosterone secretion with aging in the male rat. Biol Reprod 31: 251-258, 1984.

3. Scarbrough K and Wise PM: Age-related changes in pulsatile luteinizing hormone release precede the transition to estrousacyclicity and depend upon estrous cycle history. Endocrinology 126: 884-890, 1990. 
4. Wise PM, Dueker E and Wuttke W: Age-related alterations in pulsatile luteinizing hormone release: Effects of long-term ovariectomy, repeated pregnancies and naloxone. Biol Reprod 39: 1060-1066, 1988.

5. Kunimura Y, Iwata K, Ishigami A and Ozawa H: Age- related alterations in hypothalamic kisspeptin, neurokinin $\mathrm{B}$, and dynorphin neurons and in pulsatile LH release in female and male rats. Neurobiol Aging 50: 30-38, 2017.

6. Pinilla L, Aguilar E, Dieguez C, Millar RP and Tena-Sempere M Kisspeptins and reproduction: Physiological roles and regulatory mechanisms. Physiol Rev 92: 1235-1316, 2012.

7. Mead EJ, Maguire JJ, Kuc RE and Davenport AP: Kisspeptins: A multifunctional peptide system with a role in reproduction, cancer and the cardiovascular system. Br J Pharmacol 151: $1143-1153,2007$

8. Kotani M, Detheux M, Vandenbogaerde A, Communi D, Vanderwinden JM, Le Poul E, Brézillon S, Tyldesley R, Suarez-Huerta N, Vandeput F, et al: The metastasis suppressor gene KiSS-1 encodes kisspeptins, the natural ligands of the orphan G protein-coupled receptor GPR54. J Biol Chem 276 34631-34636, 2001

9. Lee DK, Nguyen T, O'Neill GP, Cheng R, Liu Y, Howard AD, Coulombe N, Tan CP, Tang-Nguyen AT, George SR and O'Dowd BF: Discovery of a receptor related to the galanin receptors. FEBS Lett 446: 103-107, 1999.

10. Oakley AE, Clifton DK and Steiner RA: Kisspeptin signaling in the brain. Endocr Rev 30: 713-743, 2009.

11. Shahab M, Mastronardi C, Seminara SB, Crowley WF, Ojeda SR and Plant TM: Increased hypothalamic GPR54 signaling: A potential mechanism for initiation of puberty in primates. Proc Natl Acad Sci 102: 2129-2134, 2005.

12. Seminara SB, Messager S, Chatzidaki EE, Thresher RR, Acierno JS Jr, Shagoury JK, Bo-Abbas Y, Kuohung W, Schwinof KM, Hendrick AG, et al: The GPR54 gene as a regulator of puberty. N Engl J Med 349: 1614-1627, 2003.

13. Castano JP, Martínez-Fuentes AJ, Gutiérrez-Pascual E, Vaudry H, Tena-Sempere $\mathbf{M}$ and Malagón MM: Intracellular signaling pathways activated by kisspeptins through GPR54: Do multiple signals underlie function diversity? Peptides 30: 10-15, 2009.

14. Ohtaki T, Shintani Y, Honda S, Matsumoto H, Hori A, Kanehashi K, Terao Y, Kumano S, Takatsu Y, Masuda Y, et al: Metastasis suppressor gene KiSS-1 encodes peptide ligand of a G-protein-coupled receptor. Nature 411: 613-617, 2001.

15. Muir AI, Chamberlain L, Elshourbagy NA, Michalovich D, Moore DJ, Calamari A, Szekeres PG, Sarau HM, Chambers JK, Murdock P, et al: AXOR12, a novel human G protein- coupled receptor, activated by the peptide KiSS-1. J Biol Chem 276: 28969-28975, 2001

16. Teles MG, Bianco SD, Brito VN, Trarbach EB, Kuohung W, Xu S, Seminara SB, Mendonca BB, Kaiser UB and Latronico AC: A GPR54-activating mutation in a patient with central precocious puberty. N Engl J Med 358: 709-715, 2008

17. De Roux N, Genin E, Carel JC, Matsuda F, Chaussain JL and Milgrom E: Hypogonadotropic hypogonadism due to loss of function of the KiSS1-derivedpe ptidereceptor GPR54. Proc Natl Acad Sci 100: 10972-10976, 2003.

18. Zhang G, Li J, Purkayastha S, Tang Y, Zhang H, Yin Y, Li B, Liu $G$ and Cai D: Hypothalamic programming of systemic ageing involving IKK- $\beta$, NF- $\kappa B$ and GnRH. Nature 497: 211-216, 2013.

19. Richard N, Galmiche G, Corvaisier S, Caraty A and Kottler ML: KiSS-1 and GPR54 genes are co-expressed in rat gonadotrophs and differentially regulated in vivo by oestradiol and gonadotrophin-releasing hormone. J Neuroendocrinol 20: 381-393, 2008

20. Spijker S: Dissection of rodent brain regions. Mol Cell Neurosci 57: 23-26, 2011.

21. Heffner TG, Hartman JA and Seiden LS: A Rapid method for the regional dissection of the rat brain. Pharmacol Biochem Behav 13: 453-456, 1980

22. Livak KJ and Schmittgen TD: Analysis of relative gene expression data using real-time quantitative PCR and the 2(-Delta Delta C(T)) method. Methods 25: 402-408, 2001.

23. Bradford MM: A rapid and sensitive method for the quantitation of microgram quantities of protein utilizing the principle of protein-dye binding. Anal Biochem 72: 248-254, 1976.

24. Laemmli UK: Cleavage of structural proteins during the assembly of the head of bacteriophage T4. Nature 227: 680-685, 1970

25. Arai AC, Xia YF, Suzuki E, Kessler M, Civelli O and Nothacker HP: Cancer metastasis-suppressing peptide metastin upregulates excitatory synaptic transmission in hippocampal dentate granule cells. J Neurophysiol 94: 3648-3652, 2005.
26. Welch DR, Chen P, Miele ME, McGary CT, Bower JM, Stanbridge EJ and Weissman BE: Microcell-mediated transfer of chromosome 6 into metastatic human C8161 melanoma cells suppresses metastasis but does not inhibit tumorigenicity. Oncogene 9: 255-262, 1994

27. Mattam U, Talari NK, Paripati AK, Krishnamoorthy T and Sepuri NBV: Kisspeptin preserves mitochondrial function by inducing mitophagy and autophagy in aging rat brain hippocampus and human neuronal cell line. Biochim Biophys Acta Mol Cell Res 1868: 118852, 2021

28. Gottsch ML, Cunningham MJ, Smith JT, Popa SM, Acohido BV, Crowley WF, Seminara S, Clifton DK and Steiner RA: A role for kisspeptins in the regulation of gonadotropin secretion in the mouse. Endocrinology 145: 4073-4077, 2004.

29. Kinoshita M, Tsukamura H, Adachi S, Matsui H, Uenoyama Y, Iwata K, Yamada S, Inoue K, Ohtaki T, Matsumoto $\mathrm{H}$ and Maeda K: Involvement of central metastin in the regulation of preovulatory luteinizing hormone surge and estrous cyclicity in female rats. Endocrinology 146: 4431-4436, 2005.

30. Clarkson J and Herbison AE: Postnatal development of kisspeptin neurons in mouse hypothalamus; sexual dimorphism and projections to gonadotropin-releasing hormone neurons. Endocrinology 147: 5817-5825, 2006.

31. Mikkelsen JD and Simonneaux V: The neuroanatomy of the kisspeptin system in the mammalian brain. Peptides 30: 26-33, 2009.

32. Navarro VM, Castellano JM, Fernández-Fernández R, Barreiro ML, Roa J, Sanchez-Criado JE, Aguilar E, Dieguez C, Pinilla L and Tena-Sempere M: Developmental and hormonally regulated messenger ribonucleic acid expression of KiSS-1 and its putative receptor, GPR 54, in rat hypothalamus and potent luteinizing hormone-releasing activity of KiSS-1 peptide. Endocrinology 145: 4565-4574, 2004.

33. Matsui H, Takatsu Y, Kumano S, Matsumoto $H$ and Ohtaki T: Peripheral administration of metastin induces marked gonadotropin release and ovulation in the rat. Biochem Biophys Res Commun 320: 383-388, 2004

34. Thompson EL, Patterson M, Murphy KG, Smith KL, Dhillo WS Todd JF, Ghatei MA and Bloom SR: Central and peripheral administration of kisspeptin-10 stimulates the hypothalamicpituitary-gonadal axis. J Neuroendocrinol 16: 850-858, 2004

35. Dhillo WS, Chaudhri OB, Patterson M, Thompson EL, Murphy KG, Badman MK, McGowan BM, Amber V, Patel S, Ghatei MA and Bloom SR: Kisspeptin-54 stimulates the hypothalamic-pituitary gonadal axis in human males. J Clin Endocrinol Metab 90: 6609-6615, 2005

36. Sano A and Kimura F: Electrical activity of the pulse generator of gonadotropin-releasing hormone in 26-month-old female rats. Neuroendocrinology 72: 199-207, 2000.

37. Bonavera JJ, Swerdloff RS, Leung A, Lue YH, Baravarian S, Superlano L, Sinha-Hikim AP and Wang C: In the male brown-Norway (BN) male rat, reproductive aging is associated with decreased LH-pulse amplitude and area. J Androl 18: 359-365, 1997.

38. Novaira HJ, Sonko ML and Radovick S: Kisspeptin induces dynamic chromatin modifications to control GnRH gene expression. Mol Neurobiol 53: 3315-3325, 2016.

39. Irwig MS, Fraley GS, Smith JT, Acohido BV, Popa SM, Cunningham MJ, Gottsch ML, Clifton DK and Steiner RA: Kisspeptin activation of gonadotropin releasing hormone neurons and regulation of KiSS-1mRNA in the male rat. Neuroendocrinology 80: 264-272, 2004.

40. Han SK, Gottsch ML, Lee KJ, Popa SM, Smith JT, Jakawich SK, Clifton DK, Steiner RA and Herbison AE: Activation of gonadotropin-releasing hormone neurons by kisspeptin as a neuroendocrine switch for the onset of puberty. J Neurosci 25: 11349-11356, 2005.

41. Herbison AE, de Tassigny XD, Doran J and Colledge WH: Distribution and postnatal development of Gpr54gene expression in mouse brain and gonadotropin-releasing hormone neurons. Endocrinology 151: 312-321, 2010.

42. Gonskikh Y and Polacek N: Alterations of the translation apparatus during aging and stress response. Mech Ageing Dev 168: 30-36, 2017.

43. Anisimova AS, Alexandrov AI, Makarova NE, Gladyshev VN and Dmitriev SE: Protein synthesis and quality control in aging. Aging (Albany NY) 10: 4269-4288, 2018.

44. Arai AC and Orwig N: Factors that regulate KiSS1 gene expression in the hippocampus. Brain Res 1243: 10-18, 2008. 